Research Article

\title{
Analysis of Damping Characteristics of a Hydraulic Shock Absorber
}

\author{
Zhifei Wu (D), Guangzhao Xu (D), Hongwei Yang $(\mathbb{D}$, and Mingjie Li $(\mathbb{D})$ \\ School of Mechanical and Vehicle Engineering, Taiyuan University of Technology, Taiyuan 030024, China \\ Correspondence should be addressed to Zhifei Wu; wuzhifei@tyut.edu.cn
}

Received 8 April 2020; Revised 25 August 2020; Accepted 20 October 2020; Published 26 February 2021

Academic Editor: Jörg Wallaschek

Copyright (C) 2021 Zhifei Wu et al. This is an open access article distributed under the Creative Commons Attribution License, which permits unrestricted use, distribution, and reproduction in any medium, provided the original work is properly cited.

\begin{abstract}
In the present study, a hydraulic shock absorber is proposed. Since the damper is mainly used in suspension energy recovery system, the damping characteristics of the damper under no-load state are studied in this paper. Structural design is conducted so that the unidirectional flow of the oil drives the hydraulic motor to generate electricity. Meanwhile, an asymmetrical extension/ compression damping force is obtained. A mathematical model of the shock absorber is established, and the main characteristics of the inherent damping force are obtained. Based on the established model, effects of the accumulator volume, accumulator preinflation pressure, hydraulic motor displacement, check valve inner diameter, and spring stiffness, hydraulic line length and inner diameter on the indicator characteristics are analyzed. Moreover, a series of experiments are conducted on the designed damper to evaluate the characteristics of the inherent damping force and analyze the effect of the accumulator volume and preinflation pressure on the damping characteristics.
\end{abstract}

\section{Introduction}

Conventional dampers, commonly called shock absorbers, are mainly applied to reduce the vehicle body fluctuation. During this operation, the kinetic energy originating from the body fluctuation is converted into the heat, so that the oil temperature increases. However, this temperature increment not only adversely affects the damper performance but also wastes the energy. In order to resolve this problem, numerous investigations have been conducted to study the damping characteristics. Accordingly, the dynamics of nonlinear automobile shock absorbers [1] and the evaluation of shock absorber models [2] have been proposed so far.

The hydraulic shock absorber uses the oil system to convert the vibration energy of the piston into the hydraulic energy of the damping oil, which drives the hydraulic motor in the system to rotate and drive the generator to generate the electricity $[3,4]$. Hsieh put forward a semiactive electromechanical suspension, which can control the damper requirements to recover the energy in accordance with the generating voltage of the generator. Moreover, they carried out relevant verification experiments [5, 6]. Li et al. proposed a new type of variable damping/constant damping system based on the electromagnetic damper of the motor. They showed that through the proposed scheme, the damping characteristics of the suspension system can be controlled in accordance with road conditions $[7,8]$. Xie et al. proposed an electromagnetic energy acquisition damper with 12 independent control slot winding sensors and studied the damping and energy recovery performances of the active control method for a regenerative damper [9]. Galluzzi et al. transformed the linear motion of the suspension system into the angular motion, controlled the integrated motor properly, and transformed a part of the vibration energy into the electrical energy [10]. Abdelkareem et al. conducted a comprehensive simulation on different types of vehicles (passenger, bus, trucks, and off-road vehicles) to estimate the amount of wasted energy in the vehicle suspension system. Moreover, they quantified the potential collection power of different standard driving cycles (NEDC, WLTP, HWFET, and FTP) $[11,12]$. Peng proposed a new type of hydraulic electromagnetic energy regenerative shock absorber and 
applied it in the suspension system of commercial vehicles. Then he studied the road performance of the proposed damper. To this end, he considered different affecting parameters, including the root mean square of the vertical acceleration of the spring mass, dynamic contact force between the tire and the ground, suspension deflection, maximum value of pitch angle, and the roll angle [13]. Furthermore, Xu et al. designed an energy recovery damper prototype for heavy vehicles and built a dynamic model to study damping characteristics of the designed damper. They showed that the total damping force can be divided into the resistance force, friction damping force, inertia force, and accumulator force [14]. Wu et al. studied the influence of the main parameters of the accumulator on the hydraulic system through simulation and experiment [15]. Reviewing the literature indicates that numerous researches have been performed for adjusting the damping force and improving the recovery energy efficiency. However, only a few of them focused on the influence of structural element parameters on the indicator characteristics. Because the inherent damping force produced by the element itself is uncontrollable, it is of significant importance to carefully study the influence of component parameters on the whole system and obtain the reasonable indicator characteristics.

The main purposes of the present work can be expressed as follows:

(1) Designing and analyzing a hydraulic shock absorber

(2) Evaluating the asymmetrical damping force of the designed absorber through the numerical simulation and experiment

(3) Analyzing the influence of parameters of each component on the characteristics of the designed absorber, and carrying out the test verification to optimize the indicator characteristics

\section{The Working Principle of the Hydraulic Shock Absorber}

Figure 1 illustrates the working principle of the hydraulic shock absorber. It indicates that the absorber consists of a double-acting hydraulic cylinder, a hydraulic rectifier in the form of two check valves, an accumulator, a hydraulic motor, a permanent magnetic generator, and hydraulic lines. It should be indicated that in the present study, upward and downward motions of the piston are described as compression and extension, respectively. In the compression stroke, the oil directly flows through the check valve 1 to supply the rod-end chamber, while the corresponding flow rate through the hydraulic motor depends on the rod area and the piston speed. On the other hand, the flow rate of the hydraulic motor in the extension stroke depends on the annular area of the piston and the piston speed. The flow rate drives the generator to generate electricity. The compression damping force mainly originates from the check valve 1 , while the damping force of the extension stroke primarily comes from the hydraulic motor and the check valve 2 .
Figure 1 indicates that the check valve 2 is in the closed state in the compression stroke, so that the oil directly flows through the check valve 1 to supply the rod-end chamber. It is worth noting that the volume of the rod-end chamber is smaller than that of the cap-end chamber. The oil flows through the hydraulic motor to generate electricity. Since the pressure at the left end of the check valve 2 is high and it is in the closed state, when the hydraulic motor reaches the node A, a portion of the oil is stored in the accumulator. In the extension stroke, the downward movement of the piston completely discharges the oil from the rod-end chamber. Since the check valve 1 is in the closed state, the oil can only pass through the hydraulic motor. After generating the electricity in the oil-driven hydraulic motor, the oil flows back to the cap-end chamber together with the oil in the compression stroke storage accumulator. It can be known from the principle that the overall damping force of the energy-absorbing damping force can be divided into inherent damping force and the controllable damping force. Inherent damping originates from the no-load rotational damping force of the energy feeding module, the passive damping of the accumulator, oil line, and check valve in the actuator. Moreover, the controllable damping force refers to the hydraulic motor damping force originating from the counter electromotive force of the generator.

\section{Mathematical Model}

3.1. Flow Rate Analysis. Considering the principle analysis in the foregoing section, the extension stroke flow rate can be expressed as

$$
\begin{aligned}
& Q_{\mathrm{pi}}=Q_{\mathrm{pu}}=A_{c} v(t), \\
& Q_{v 1}=0 \\
& Q_{v 2}=A_{g} v(t) .
\end{aligned}
$$

Furthermore, the compression stroke flow is

$$
\begin{aligned}
& Q_{v 1}=\left|A_{g} v(t)\right|, \\
& Q_{\mathrm{pi}}=Q_{\mathrm{pu}}=\left|A_{r} v(t)\right|, \\
& Q_{v 2}=0,
\end{aligned}
$$

where $Q_{\mathrm{pi}}$ and $Q_{\mathrm{pu}}$ are the flow rate through the hydraulic line and pump, respectively. Moreover, $Q_{v 1}$ and $Q_{v 2}$ denote the flow rate through the check valves 1 and 2 , respectively. Meanwhile, $A_{c}$ is the annular area of the piston, $A_{c}=A_{g}-A_{r}=\pi\left(D^{2}-d_{\text {rod }}^{2}\right) / 4 . v(t)$ is the moving speed of the piston, $A_{g}$ is the piston face area, $A_{g}=\pi D^{2} / 4$, and $A_{r}$ is the piston rod area, $A_{r}=\pi d_{\text {rod }}^{2} / 4$, where $D$ and $d_{\text {rod }}$ are the diameter of piston and piston rod, respectively.

The correlation between the hydraulic motor speed and torque can be expressed as 


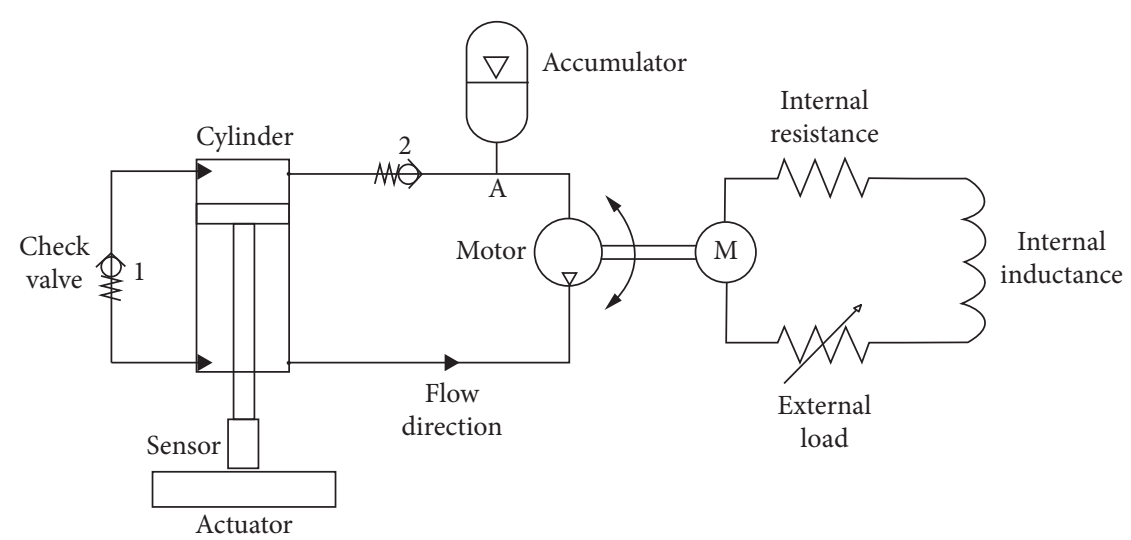

Figure 1: Configuration of the half-bridge hydraulic energy-harvesting shock absorber.

$$
\begin{gathered}
\omega_{\mathrm{pu}}=\frac{2 \pi \mathrm{Q}_{\mathrm{pu}}}{q} \eta_{v}, \\
T_{\mathrm{pu}}=\frac{\Delta P_{\mathrm{pu}} q}{2 \pi} \eta_{m},
\end{gathered}
$$

where $\omega_{\mathrm{pu}}$ is the rotating speed of the hydraulic motor, $T_{\mathrm{pu}}$ is the torque of the hydraulic motor, $Q_{p u}$ is the flow rate through the hydraulic motor, and $q$ is the motor displacement. Moreover, $\Delta P_{\text {pu }}$ is the pressure difference of hydraulic motor inlet and the outlet oil, $\eta_{v}$ is the volumetric efficiency of the hydraulic motor, and $\eta_{m}$ is the mechanical efficiency of the hydraulic motor.

When the hydraulic motor drives the generator to rotate through the coupling, the correlation between the generator output voltage $U_{\mathrm{emf}}$ and the generator drive torque $T_{g}$ can be expressed in the form below:

$$
\begin{aligned}
U_{\mathrm{emf}} & =k_{e} \omega_{g}, \\
T_{g} & =J_{g} \frac{\mathrm{d} \omega}{\mathrm{d} t}+k_{t} I,
\end{aligned}
$$

where $\omega_{g}$ is the generator rotating speed. Moreover, $k_{e}$ and $k_{t}$ are the generator's counter electromotive force constant and torque constant, respectively. Furthermore, $J_{g}$ denotes the inertia of the generator rotor, and $I$ is the generator output current.

According to Kirchhoff's voltage law, the following expression can be written as

$$
U_{\mathrm{emf}}-L_{\mathrm{in}} \frac{\mathrm{d} I}{\mathrm{~d} t}-I\left(R_{\mathrm{in}}+R_{\mathrm{ex}}\right)=0
$$

where $L_{\text {in }}$ is the generator internal inductance, $R_{\text {in }}$ is the generator internal resistance, and $R_{\mathrm{ex}}$ is the external generator load. It is worth noting that the internal inductance of the generator is normally ignored in the calculations.

Since the hydraulic motor and the generator are connected by the coupling,

$$
\begin{aligned}
& \omega_{\mathrm{pu}}=\omega_{g}, \\
& T_{\mathrm{pu}}=T_{g} .
\end{aligned}
$$

Based on equations (7)-(13), the hydraulic pressure drops $\Delta P_{\text {pu }}$ between the inlet and outlet of the hydraulic motor, and the flow rate of the oil $Q_{p u}$ flowing through the hydraulic motor can be obtained as follows:

$$
\Delta P_{\mathrm{pu}}=\frac{4 \pi^{2} J_{g} \eta_{v}}{q^{2} \eta_{m}} \dot{Q}_{\mathrm{pu}}+\frac{4 \pi^{2} k_{t} k_{e} \eta_{v}}{q^{2} \eta_{m}\left(R_{\mathrm{in}}+R_{\mathrm{ex}}\right)} Q_{\mathrm{pu}} .
$$

\subsection{Inherent Damping Force}

3.2.1. Pressure Drop Calculation of the Motor at the No-Load Condition. In the foregoing section, an expression for the motor pressure drop was obtained. When the external resistor is infinite, as the research literature show [16], the hydraulic pressure drop between the inlet and outlet of the hydraulic motor and the flow rate at the no-load can be written as

$$
\Delta P_{\text {pup }}=\frac{4 \pi^{2} J_{g} \eta_{v}}{q^{2} \eta_{m}} \dot{Q}_{\mathrm{pu}}=c_{\mathrm{pp}} \dot{\mathrm{Q}}_{\mathrm{pu}}
$$

where $\Delta P_{\text {pup }}$ and $Q_{\text {pu }}$ are the pressure drop between the inlet and outlet of the hydraulic motor and the flow rate of the hydraulic motor, respectively. $c_{\mathrm{pp}}$ denote the equivalent inherent damping of the feed module.

Moreover, $c_{\mathrm{pp}}$ is related to the temperature variation in practical work [17], as the damper oil temperature strongly influences the oil viscosity and consequently the damping force to be determined. The internal energy of the damper oil is going to be increased by passing through the orifices of shock absorber, and hence the temperature needs to be taken into account. When taking the temperature-dependent oil viscosity into account, the rising temperature makes $c_{\mathrm{pp}}$ decrease; however, the temperature increase is not unlimited 
[18]. When the damper obtains thermal balance, $c_{\mathrm{pp}}$ is approximately a constant. In this model, only the oil temperature under thermal balance is taken into account.

3.2.2. Calculation of the Pressure Drop at the Hydraulic Line. The pressure drop at the hydraulic line $\Delta P_{\mathrm{pi}}$ can be expressed as

$$
\Delta p_{\mathrm{pi}}=\frac{128 \rho L_{\mathrm{pi}} \mu}{\pi d_{\mathrm{pi}}^{4}} Q_{\mathrm{pi}}=k_{\mathrm{pi}} Q_{\mathrm{pi}} \text {, }
$$

where $\rho$ represents the oil density; $k_{\mathrm{pi}}$ is the coefficient of the pipeline pressure drop; $Q_{p i}$ is the oil flow rate in the pipeline; $L_{\mathrm{pi}}$ and $d_{\mathrm{pi}}$ are the hydraulic pipe length and diameter, respectively; and $\mu$ is the dynamic viscosity of the oil.

3.2.3. Calculating the Pressure Drop in the Check Valve. The oil flows through the check valve, and the pressure drop of the check valve can be calculated through the orifice equation:

$$
\Delta P_{v i}=\left(\sqrt{\frac{\rho}{2}} \frac{K_{v i}}{C_{d} B_{v i} A_{v i}} Q_{v i}\right)^{(2 / 3)},
$$

where $Q_{v i}, i=1,2$, represents the flow rate through the check valve $i ; \Delta P_{v i}$ denotes the pressure difference between the inlet and outlet of the check valve; and $C_{d}$ is the flow coefficient. Moreover, $B_{V i}, A_{V i}$, and $K_{v i}$ denote the valve blade perimeter, area, and stiffness of the check valve $i$, respectively.

3.2.4. Accumulator. A certain mass of gas exists in the accumulator. Based on the governing equations on the ideal gas, the correlation between the gas volume and the pressure is

$$
\begin{aligned}
F_{p} & =A_{c} P_{\text {downp }}-A_{g} P_{\text {upp }} \\
& =A_{c}\left(\Delta P_{\text {pup }}+P_{t}+\Delta P_{\text {pi }}\right)-A_{g}\left(P_{t}-\Delta P_{v 2}\right), v(t) \geq 0 \\
& =A_{c}\left(\Delta P_{\text {pup }}+P_{t}+\Delta P_{\text {pi }}\right)-A_{g}\left(\Delta P_{\text {pup }}+P_{t}+\Delta P_{\text {pi }}+\Delta P_{v 1}\right), v(t) \leq 0,
\end{aligned}
$$

which is

$$
\begin{aligned}
F_{p} & =\frac{\pi^{4} J_{g} \eta_{v}}{4 q^{2} \eta_{m}}\left(D^{2}-d_{\mathrm{rod}}^{2}\right)^{2} \dot{v}(t)-\frac{\pi P_{0} V_{0}^{n} d_{\mathrm{rod}}^{2}}{4\left(V_{0}+(\pi / 4) d_{\mathrm{rod}}^{2} \int v(t) \mathrm{d} t\right)^{n}}+\frac{32 \rho L_{\mathrm{pi}} \mu}{d_{\mathrm{pi}}^{4}}\left(D^{2}-d_{\mathrm{rod}}^{2}\right)^{2} v(t)+\frac{\pi}{8} \rho^{1 / 3}\left(\frac{K_{v 2}}{C_{d} d_{v 2} A_{v 2}}\right)^{2 / 3} D^{11 / 3} v(t)^{2 / 3}, \\
v(t) & \leq 0 \\
& =\frac{\pi^{4} J_{g} \eta_{v}}{4 q^{2} \eta_{m}} d_{\mathrm{rod}}^{4} \dot{v}(t)-\frac{\pi P_{0} V_{0}^{n} d_{\text {rod }}^{2}}{4\left(V_{0}+(\pi / 4) d_{\mathrm{rod}}^{2} \int v(t) \mathrm{d} t\right)^{n}}-\frac{32 \rho L_{\mathrm{pi}} \mu}{d_{\mathrm{pi}}^{4}} d_{\mathrm{rod}}^{4} v(t)-\frac{\pi}{8} \rho^{1 / 3}\left(\frac{K_{v 2}}{C_{d} d_{v 2} A_{v 2}}\right)^{2 / 3} D^{11 / 3} v(t)^{2 / 3}, v(t) \leq 0 .
\end{aligned}
$$




\section{Simulation and Analysis of the Damping Force}

4.1. Indicator Characteristics under No-Load Condition. According to the theoretical analysis of the hydraulic shock absorber, the inherent damping force of the damper is affected by the excitation frequency. Therefore, this section discusses the indicator characteristic at different excitation frequencies and different excitation amplitudes under noload conditions. It should be indicated that the mathematical model is established, and the simulation parameters are set to the excitation amplitude of $50 \mathrm{~mm}$ and $20 \mathrm{~mm}$. The excitation frequencies are set to $0.45 \mathrm{~Hz}, 0.62 \mathrm{~Hz}, 1 \mathrm{~Hz}$, and $2 \mathrm{~Hz}$. According to the sinusoidal excitation of the shock absorber, the peak value of damping force and the peak value of excitation velocity appear at the same time, and the corresponding peak value of each excitation frequency is $0.14 \mathrm{~m} / \mathrm{s}, 0.19 \mathrm{~m} / \mathrm{s}, 0.31 \mathrm{~m} / \mathrm{s}$, and $0.63 \mathrm{~m} / \mathrm{s}$. Moreover, the external load is set to infinity. Figures 2 and 3 show the indicator characteristics of the no-load condition at different peak excitation velocity and different excitation amplitudes.

Figures 2 and 3 show that the extension stroke damping force is higher than the compression stroke, which is consistent with the asymmetric damping characteristics required by the conventional damper. Moreover, under the no-load condition, as the extension frequency and excitation amplitude increase, both the extension stroke and the compression stroke damping force increase. Furthermore, the extension stroke is relatively obvious. The damping force rises slowly in the first half of the compression stroke, and the damping force rises quickly in the second half of the extension stroke, which causes the indicator chart not to be full and affects the damping characteristics. In the next section, the influence of different parameters on the indicator characteristic is studied.

\subsection{Simulation Analysis of Influencing Factors of the Damping} Force. According to the mathematical model of the compression damping force and the extension damping force, the factors affecting the damping force include check valve blade perimeter $B_{v i}$, area $A_{V i}$, and stiffness $K_{v i}$, hydraulic pipe length $L_{\mathrm{pi}}$ and diameter $d_{\mathrm{pi}}$, gas pressure $P_{0}$, and volume $V_{0}$ in the accumulator in the initial state and hydraulic motor displacement $q$. Under the condition that the excitation frequency is $0.45 \mathrm{~Hz}$ and the excitation amplitude is $50 \mathrm{~mm}$, the single-parameter variation method is used in the simulation test to analyze the influence of each parameter on the indicator characteristics of the hydraulic shock absorber.

Figures 4-8 illustrate that the gas volume of the accumulator has little impact on the main characteristics. The accumulator preinflation pressure has a significant influence on extension stroke and compression stroke. Increasing the preinflation pressure appropriately can increase the compression stroke damping force, reduce the extension stroke damping force, and improve the feeding efficiency. However, the system response will be slowed down, and the damping force hysteresis will increase when the hydraulic

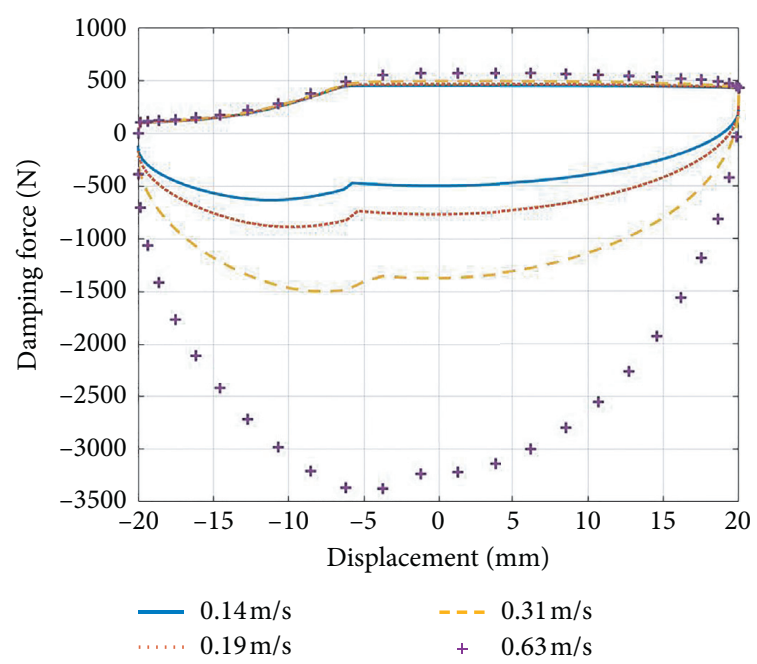

Figure 2: Indicator characteristic of $20 \mathrm{~mm}$ excitation amplitude at different excitation frequencies.

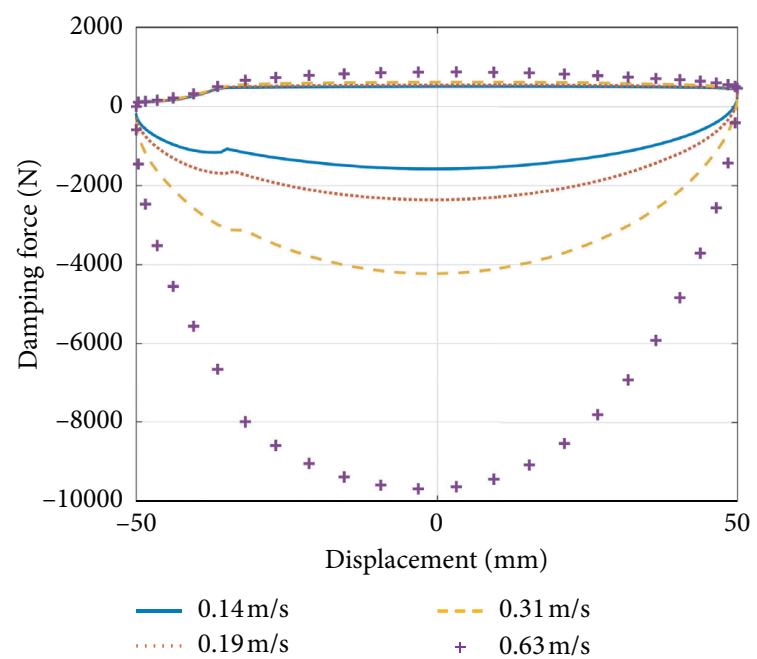

FIgURE 3: Indicator characteristic of $50 \mathrm{~mm}$ excitation amplitude at different excitation frequencies.

cylinder is reversed. Moreover, the damping force impact will increase in the second half of the extension stroke. As the displacement of the hydraulic motor decreases, the damping force of the recovery stroke increases significantly. Increasing the flow of the check valves and reducing the opening pressure of the check valves can effectively reduce the damping force of the corresponding stroke. Furthermore, it is observed that shortening the pipe length and reducing the pipe diameter can effectively improve the response speed of the system.

\section{Experimental Methodologies}

5.1. Experimental Setup. In order to evaluate the effects of different excitation speeds and structural element parameters, a hydraulic energy-harvesting shock absorber test bench is constructed in the present study. Meanwhile, the existing hydraulic excitation platform is used to simulate the 


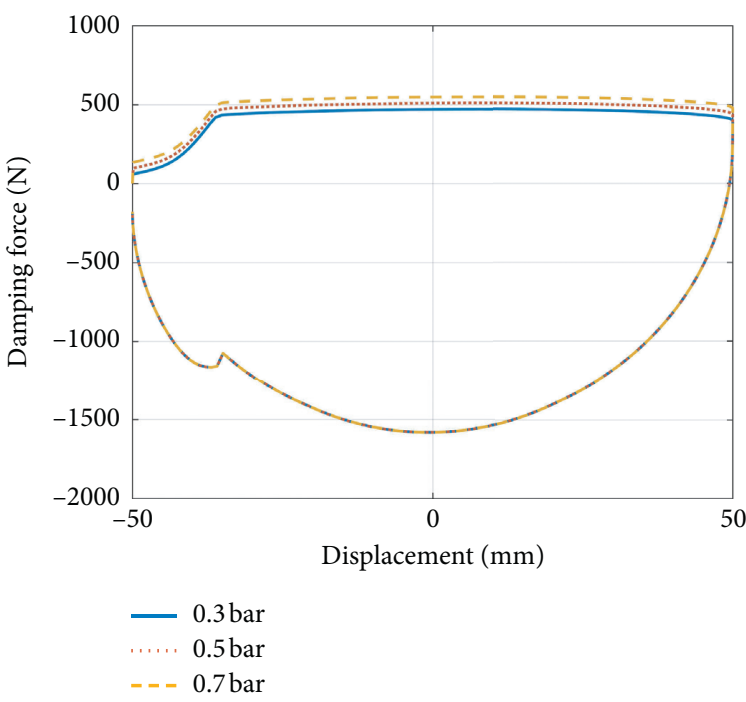

(a)

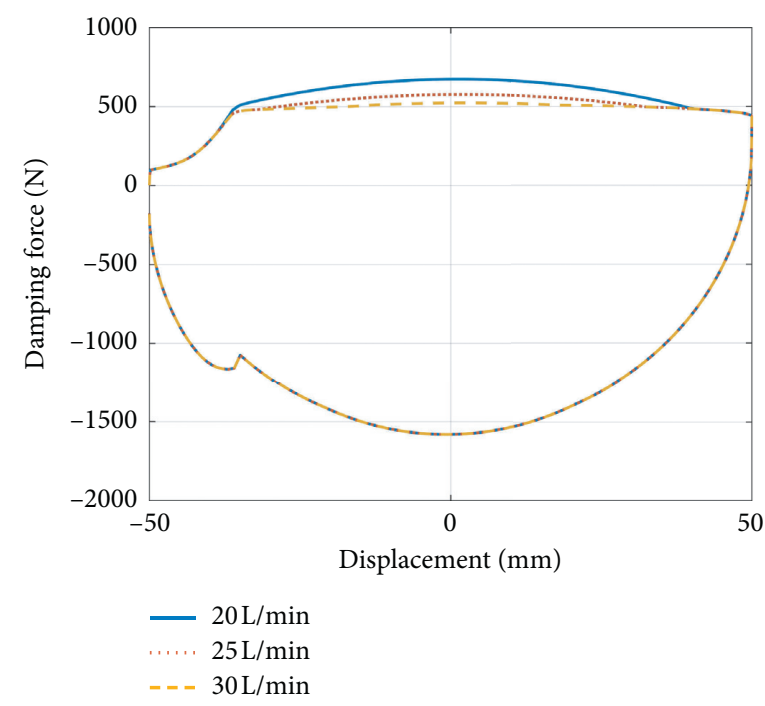

(b)

FIGURE 4: Influence of check valve 1 opening pressure (a) and flow (b) on indicator characteristic.

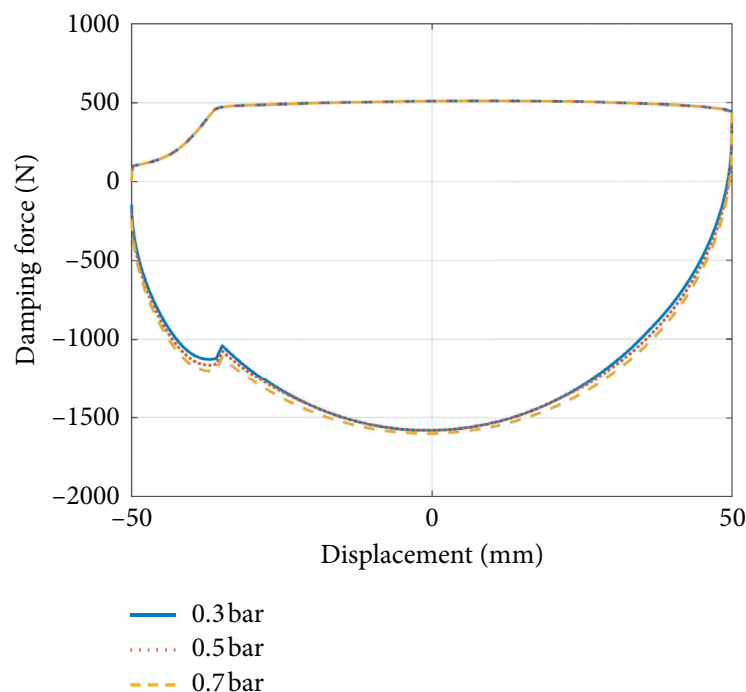

(a)

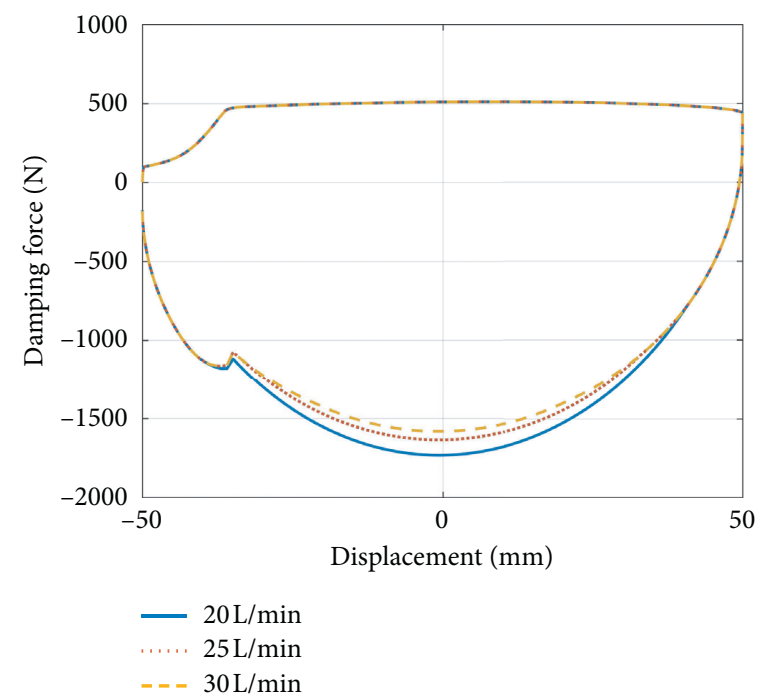

(b)

Figure 5: Influence of check valve 2 opening pressure (a) and flow (b) on indicator characteristic.

road excitation. The test bench is mainly composed of a double-acting hydraulic cylinder, check valves, accumulator, hydraulic motor, generator, high-power sliding rheostat, and compression and tension load sensor. Figure 9 shows the schematic diagram of the hydraulic energy-harvesting shock absorber.

The abovementioned theory analysis and simulation show that the inherent damping force of the shock absorber is affected by the excitation frequency. Therefore, the damping force at the same excite displacement and different excite velocities is investigated experimentally under no-load condition. Since the excitation platform used in the experiment cannot provide sinusoidal excitation, the experiment adopts uniform excitation. Moreover, the maximum speed of the sinusoidal excitation is the same as the experimental excitation speed under the simulation condition. Table 1 shows the experimental setting.

5.2. Experimental Procedure. The hydraulic excitation platform is adjusted to set the excitation speed. This is performed by changing the accumulator of different volumes and adjusting the gas pressure inside the accumulator. The values of the compression and tension load from the sensor are collected using a data acquisition instrument, which is discussed below. 


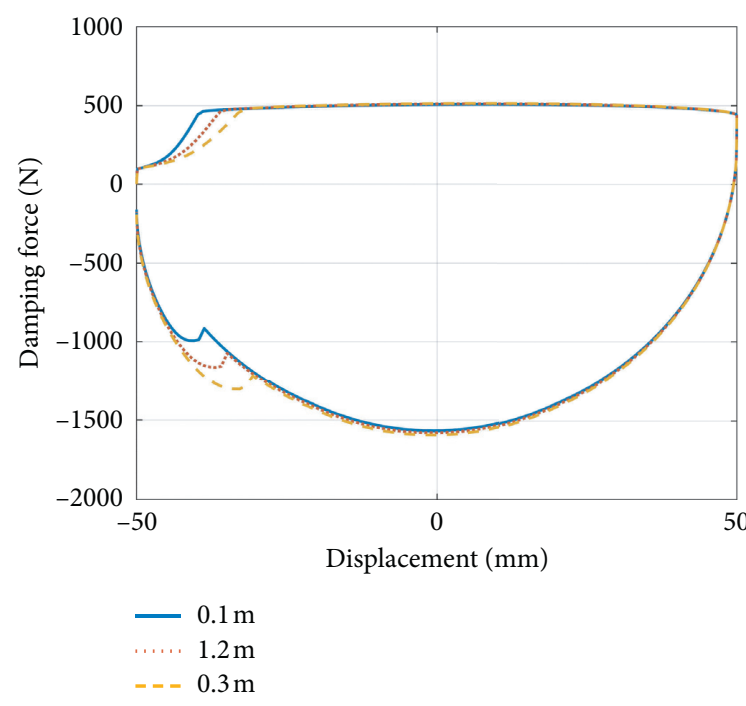

(a)

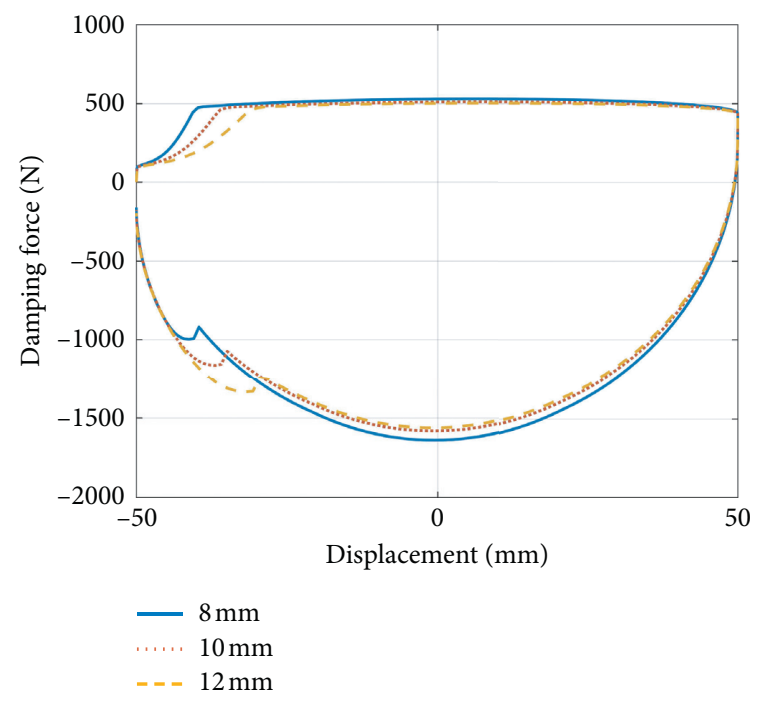

(b)

FIGURE 6: Influence of length of each part of the pipeline (a) and inner diameter of each part (b) on indicator characteristic.

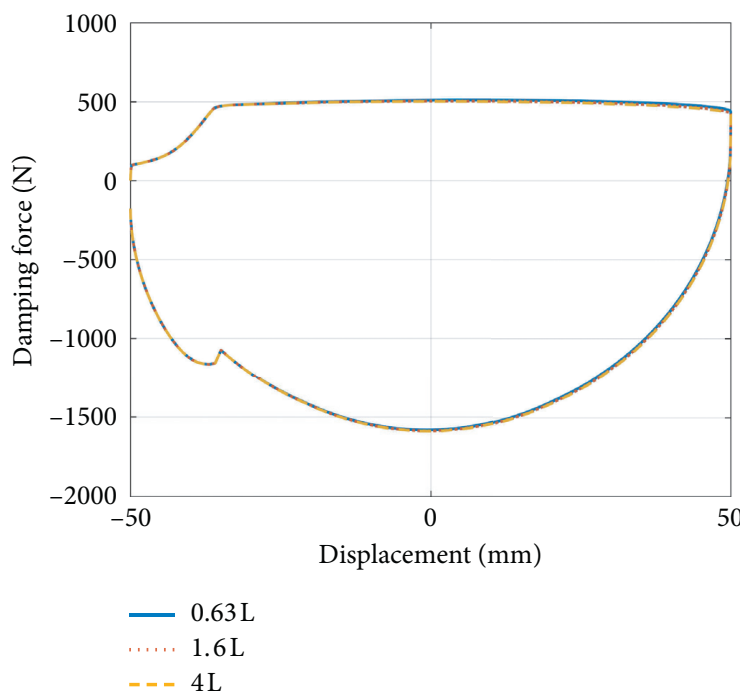

(a)

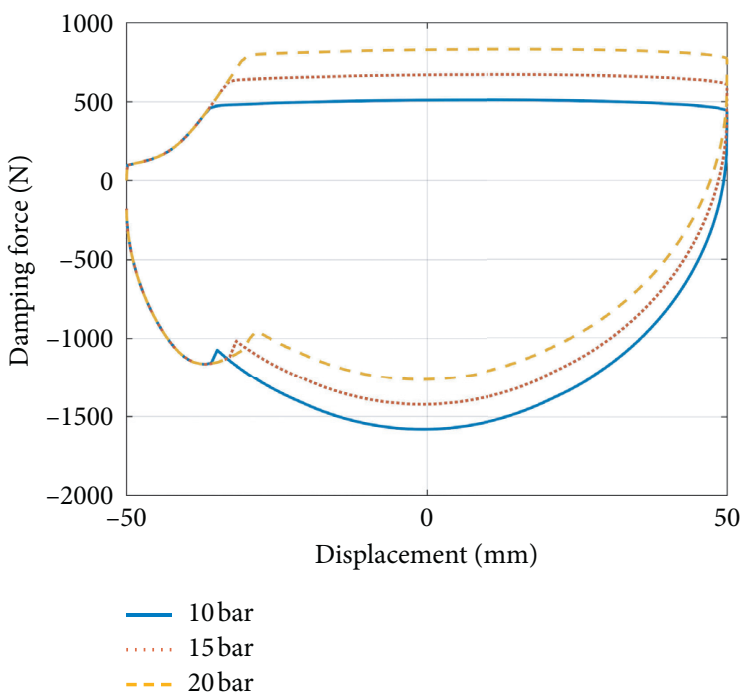

(b)

FIGURE 7: Influence of gas volume (a) and preinflation pressure (b) on indicator characteristic.

5.3. Data Acquisition. In this study, an INV3060A 16channel data acquisition instrument is utilized for collecting data. Moreover, the DYLY-103 load cell is used as the compression and tension load sensor. During the experiment, a DASP system is used to collect and display the values obtained from the compression and tension load sensor.

\section{Experimental Results and Discussion}

6.1. Indicator Characteristic under No-Load Condition Verification. This section discusses the experimental study of the indicator characteristic under no-load condition of the excitation amplitude of $50 \mathrm{~mm}$ and different excitation speeds.
Figure 10 shows that in the test data, the damping force of the extension stroke is larger than the damping force of the compression stroke, which is consistent with the asymmetric damping characteristics required by the conventional shock absorber. The model is verified by the experimental results and simulation results. The experimental and simulation data have reasonable agreement. However, results obtained from the experiment are slightly higher than that of the simulation. The reason is that the simulation is based on ideal conditions. In actual conditions, due to the low oil temperature, the pipe joint and the flow meter will inevitably cause a certain energy loss. As the excitation speed increases, the damping force of the compression stroke and extension stroke increases. 


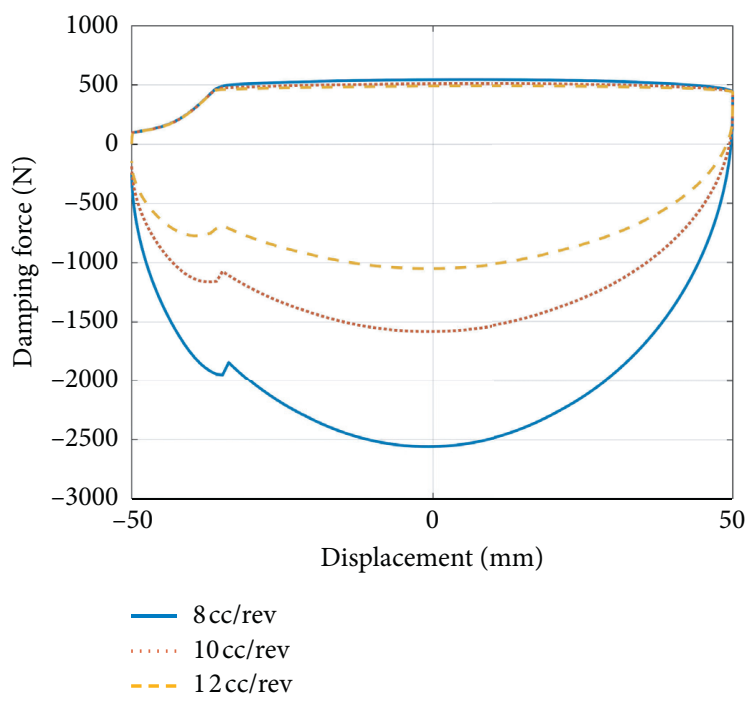

FIGURE 8: Influence of motor displacement on indicator characteristic.

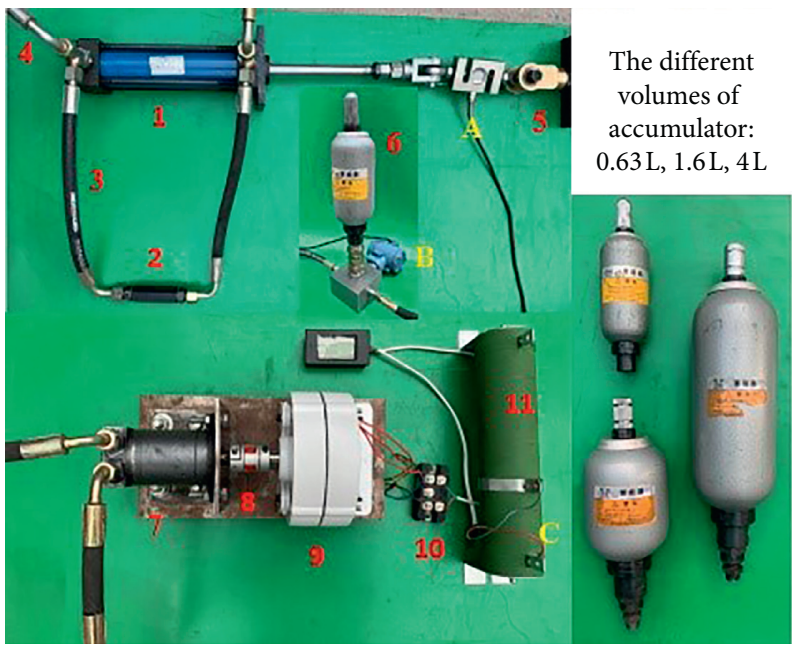

FIgURE 9: Key components of the hydraulic energy-harvesting shock absorber systems. 1. Hydraulic cylinder 2,4. Check valve 3. Hose 5. Hydraulic excitation platform 6. Accumulator 7. Hydraulic motor 8. Coupling 9. Three-phase alternator 10. Rectifier 11. Sliding rheostat A. Force Transductor B. Pressure Transductor C. Voltage Transductor.

Moreover, the recovery stroke increases significantly. In the first half of the extension stroke, the damping force has an impact because of the pressure impact caused by the release pressure of the accumulator at the moment when the hydraulic cylinder changes direction. Moreover, the impact increases as the excitation speed increases.

6.2. Accumulator Influence Factor Verification. In this test, the univariate method is adopted, and the hydraulic energyharvesting shock absorber principle prototype is used as the platform. Under the same conditions, the accumulator
TABLE 1: Main component parameters of the hydraulic excitation system.

\begin{tabular}{|c|c|c|c|c|c|}
\hline Parameters & \multicolumn{4}{|c|}{ Value } & Unit \\
\hline Displacement & \multicolumn{4}{|c|}{ \pm 50} & $\mathrm{~mm}$ \\
\hline Speed & 0.19 & 0.14 & 0.11 & 0.07 & $\mathrm{~m} / \mathrm{s}$ \\
\hline Frequency & 0.62 & 0.45 & 0.35 & 0.23 & $\mathrm{~Hz}$ \\
\hline
\end{tabular}

volume and the preinflation pressure are changed to observe the variation of the compression stroke and the extension stroke damping force. Complete real-time acquisition and display of the damping force are obtained during the experiment. 


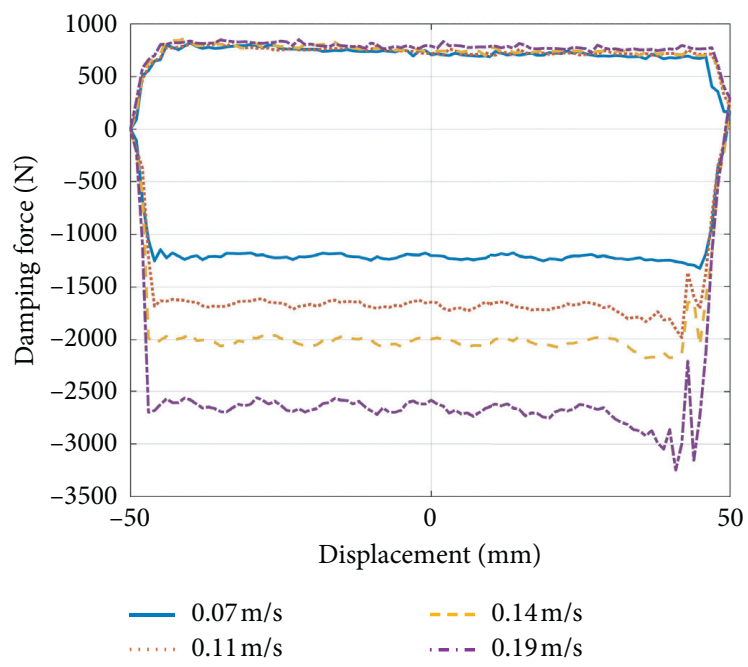

FIgURE 10: Indicator characteristic of no-load condition at different extension speeds.

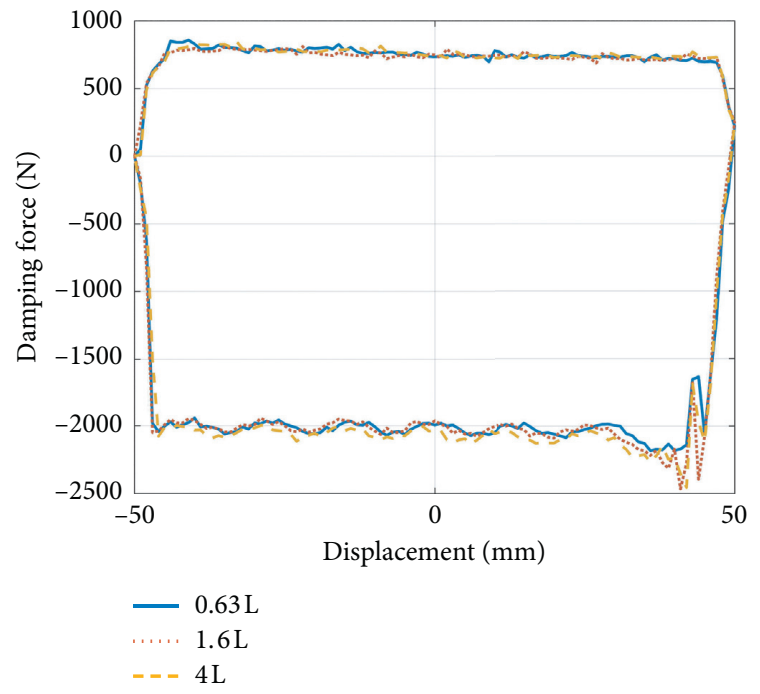

FIGURE 11: Influence of gas volume on indicator characteristic.

In order to compare the influence of different volumes of the accumulator on the damping force, the test utilizes the excitation speed of $0.14 \mathrm{~m} / \mathrm{s}$, the preinflation pressure of $1 \mathrm{MP}$, and the accumulator volumes of $0.63 \mathrm{~L}, 1.6 \mathrm{~L}$, and $4 \mathrm{~L}$ respectively. Figure 11 shows the obtained result.

In order to compare the influence of different preinflation pressures on the damping force of the accumulator, the test uses an excitation speed of $0.14 \mathrm{~m} / \mathrm{s}$, an accumulator volume of $0.63 \mathrm{~L}$, and preinflation pressures of $10 \mathrm{bar}, 15 \mathrm{bar}$, and 20 bar respectively. Figure 12 shows the test results.

Figures 11 and 12 show that the gas volume of the accumulator has little effect on the indicator characteristic. As the volume decreases, the damping force of the extension stroke increases slightly. The accumulator preinflation pressure has a significant influence on the compression stroke and the extension stroke damping force. As the accumulator pressure increases, the compression stroke damping force increases, and the extension stroke damping

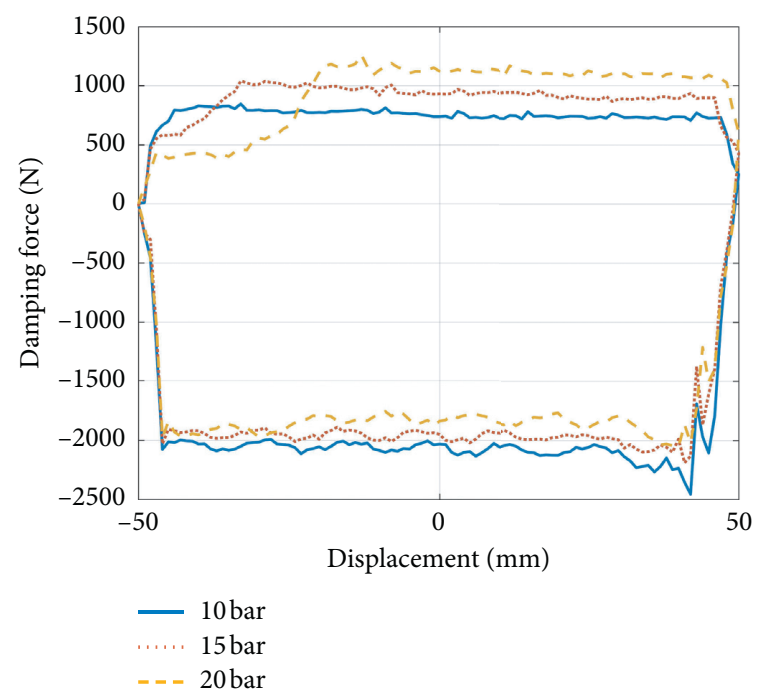

FIGURE 12: Influence of the preinflation pressure on indicator characteristic.

force decreases. Moreover, the controllable damping force of the extension stroke, the recoverable power, and efficiency are reduced. As the accumulator preinflation pressure decreases, the response time of the first half of the compression stroke is shortened. Furthermore, the damping force hysteresis decreases when the hydraulic cylinder is reversed, and the damping force impact increases in the second half of the extension stroke.

\section{Conclusions}

In the present study, a hydraulic shock absorber is proposed. Moreover, its design principle and mathematical model are described in detail. The principle prototype is constructed to verify the damping characteristics of the proposed shock absorber. The main conclusions are as follows: 
(1) The hydraulic shock absorber can obtain an asymmetrical extension/compression damping force. The damping force depends on the excitation speed. At the excitation speed ranging from 0.07 to $0.19 \mathrm{~m} / \mathrm{s}$, the compression stroke damping force and the extension stroke damping force range from 720 to $790 \mathrm{~N}$ and -1210 to $-2660 \mathrm{~N}$, respectively.

(2) The inherent damping force depends on the element parameters. The flow and opening pressures of the check valves can influence the damping force of the corresponding stroke. Moreover, the pipe length and pipe diameter can influence the response speed of the system. The displacement of the hydraulic motor and the accumulator preinflation pressure has a significant influence on the damping force. It should be indicated that better damping force characteristics can be obtained by adjusting the preinflation pressure of the accumulator reasonably.

\section{Data Availability}

The data used to support the findings of the study are original and available within the article.

\section{Conflicts of Interest}

The authors declare no conflict of interest.

\section{Authors' Contributions}

Zhifei Wu contributed to the methodology; Guangzhao Xu validated the study; Hongwei Yang and Mingjie Li performed data processing; all the authors have read and approved the final manuscript.

\section{Acknowledgments}

The authors are grateful for the support by the Vehicle Department of Taiyuan University of Technology. This research was funded by the Shanxi Province Science and Technology Major Project, grant number: 20181102006.

\section{References}

[1] J. Wallaschek, "Dynamics of non-linear automobile shockabsorbers," International Journal of Non-linear Mechanics, vol. 25, no. 2-3, pp. 299-308, 1990.

[2] S. Duym, R. Stiens, K. Reybrouck et al., "Evaluation of shock absorber models," Vehicle System Dynamics, vol. 27, no. 2, pp. 109-127, 1997.

[3] Z. Gao, S. Chen, Y. Zhao, and Z. Liu, "Numerical evaluation of compatibility between comfort and energy recovery based on energy flow mechanism inside electromagnetic active suspension," Energy, vol. 170, pp. 521-536, 2019.

[4] J. Liu, X. Li, X. Zhang, and X. Chen, "Modeling and simulation of energy-regenerative active suspension based on BP neural network PID control," Shock and Vibration, vol. 2019, Article ID 4609754, 8 pages, 2019.

[5] C.-Y. Hsieh, B. Huang, F. Golnaraghi, and M. Moallem, "Regenerative skyhook control for an electromechanical suspension system using a switch-mode rectifier," IEEE
Transactions on Vehicular Technology, vol. 65, no. 12, pp. 9642-9650, 2016.

[6] C.-Y. Hsieh, M. Moallem, and F. Golnaraghi, "A bidirectional boost converter with application to a regenerative suspension system," IEEE Transactions on Vehicular Technology, vol. 65, no. 6, pp. 4301-4311, 2016.

[7] S. Li, J. Xu, X. Pu et al., "Energy-harvesting variable/constant damping suspension system with motor based electromagnetic damper," Energy, vol. 189, pp. 116-199, 2019.

[8] S. Li, J. Xu, X. Pu, T. Tao, and X. Mei, "A novel design of a damping failure free energy-harvesting shock absorber system," Mechanical Systems and Signal Processing, vol. 132, pp. 640-653, 2019.

[9] L. Xie, J. Li, S. Cai, and X. Li, "Electromagnetic energy-harvesting damper with multiple independently controlled transducers: on-demand damping and optimal energy regeneration," IEEE/ASME Transactions on Mechatronics, vol. 22, no. 6, pp. 2705-2713, 2017.

[10] R. Galluzzi, Y. Xu, N. Amati, and A. Tonoli, "Optimized design and characterization of motor-pump unit for energyregenerative shock absorbers," Applied Energy, vol. 210, pp. 16-27, 2018.

[11] M. A. A. Abdelkareem, L. Xu, X. Guo et al., "Energy harvesting sensitivity analysis and assessment of the potential power and full car dynamics for different road modes," Mechanical Systems and Signal Processing, vol. 110, pp. 307-332, 2018.

[12] M. A. A. Abdelkareem, L. Xu, M. K. A. Ali et al., "Vibration energy harvesting in automotive suspension system: a detailed review," Applied Energy, vol. 229, pp. 672-699, 2018.

[13] M. Peng, X. Guo, J. Zou et al., "Simulation study on vehicle road performance with hydraulic electromagnetic energyregenerative shock absorber," Wuhan University of Technology, Wuhan, China, SAE Technical Paper, 2016.

[14] S. Guo, L. Xu, Y. Liu, X. Guo, and L. Zuo, "Modeling and experiments of a hydraulic electromagnetic energy-harvesting shock absorber," IEEE/ASME Transactions on Mechatronics, vol. 22, no. 6, pp. 2684-2694, 2017.

[15] Z. Wu, Y. Xiang, M. Li, M. Y. Iqbal, and G. Xu, "Investigation of accumulator main parameters of hydraulic excitation system," Journal of Coastal Research, vol. 93, no. sp1, pp. 613-622, 2019.

[16] M. Siba, W. Wanmahmood, M. Z. Nuawi et al., "Flow-induced vibration in pipes: challengess and solutions-a review," Journal of Engineering Ence \& Technology, vol. 11, no. 3, pp. 362-382, 2016.

[17] G. Yu, C. Du, T. Sun et al., "Thermodynamic behaviors of a kind of self-decoupling magnetorheological damper," Shock and Vibration, vol. 2015, Article ID 502747, 9 pages, 2015.

[18] J. C. Ramos, A. Rivas, J. Biera, G. Sacramento, and J. A. Sala, "Development of a thermal model for automotive twin-tube shock absorbers," Applied Thermal Engineering, vol. 25, no. 11-12, pp. 1836-1853, 2005. 